\title{
Gemella bergeri
}

National Cancer Institute

\section{Source}

National Cancer Institute. Gemella bergeri. NCI Thesaurus. Code C86890.

A species of facultatively anaerobic, Gram positive, cocci shaped bacteria assigned to the phylum Firmicutes. This species does not form endospores, is oxidase and catalase negative, non motile, and produces phosphoamidase. G. bergeri does not produce acid from maltose or sucrose. 